\title{
Global Research Trends of Herbal Medicine for Pain in Three Decades (1990-2019): A Bibliometric Analysis
}

\author{
Chennan Wang $\mathbb{1}^{1}$ \\ Qinggang Meng $\mathbb{D}^{2}$
}

'School of Traditional Chinese Medicine, Beijing University of Chinese Medicine, Beijing, People's Republic of China; ${ }^{2}$ System Complexity Research Center of Chinese Medicine, Beijing University of Chinese Medicine, Beijing, People's Republic of China
Correspondence: Chennan Wang School of Traditional Chinese Medicine, Beijing University of Chinese Medicine, II Bei San Huan Dong Lu, Chaoyang District, Beijing, 100029, People's Republic of China $\mathrm{Tel}+8618801198973$

Email IvanWangBUCM@hotmail.com
Purpose: The aim of this study was to explore the global research trends of herbal medicine for pain from 1990 to 2019, using bibliometric methods, and explore international collaborations, intellectual structure, the evolution of active topics, emerging trends, and research frontiers.

Methods: Articles on herbal medicine for pain were retrieved from WoSCC. Two information visualization softwares including CiteSpace and HistCite were used to process bibliographic catalogs. Identification of international collaborations, intellectual structure, the evolution of active topics, emerging trends, and research frontiers were performed based on results from bibliometric analysis.

Results: A total of 2986 original articles published between 1990 and 2019 were identified based on the inclusion criteria. The number of publications on herbal medicine for pain in WoSCC significantly increased. China ranked highest in the number of scientific outputs; however, articles with the highest citation rates were found to be from the United States. China-Japan reported the most active collaborations, whereas Kyung Hee University from South Korea was the most productive institution. Zhang Y was the most productive author, whereas research by Sherman KJ and Vane JR had the highest influence. Journal of Ethnopharmacology was the most active journal, whereas Integrative and Complementary Medicine was the most active research area. History of herbal medicine for pain research comprises three major phases of activities. The main points of focus of bibliometric analysis of herbal medicine for pain include "knee osteoarthritis", "cancer", "low back pain", etc.. Moreover, research on mechanisms of action of herbal medicine for pain remains at the forefront of this field.

Conclusion: This paper provides a basis for future development of research on herbal medicine for pain, which may help researchers explore new directions for future research and identify new perspectives on potential collaborations in this field.

Keywords: herbal medicine, pain, bibliometric analysis, CiteSpace, HistCite, international collaborations, traditional medicine

\section{Introduction}

Pain is a significant public health concern. The Centers for Disease Control and Prevention (CDC) reports that approximately 100 million Americans - more than the number affected by cardiovascular disease, diabetes, and cancer combined suffer from common chronic pain conditions. ${ }^{1}$ Studies report that the prevalence of chronic pain ranges between $11 \%$ and $40 \%{ }^{2}$ According to the CDC, 50 million adults in the United States experience chronic daily pain, with 19.6 million adults 
experiencing high impact chronic pain that interferes with their daily life or work activities. ${ }^{3}$ Chronic pain is linked to numerous physical and mental conditions and contributes to high health care costs and loss of productivity. ${ }^{4}$ In the United States, the estimated cost for pain management ranges from $\$ 560$ billion to $\$ 635$ billion annually., Opioids are commonly prescribed drugs for chronic pain, and in the United States, the most recent national data show a fourfold increase in opioid prescriptions in the early 2000s, accompanied by an increase in opioidrelated overdose and misuse. ${ }^{7,8}$ In 2018, opioids were implicated in 46,802 overdose deaths in the United States (69.5\% of all drug overdose deaths). ${ }^{9}$ Gastrointestinal discomfort is the most common side effect of nonsteroidal anti-inflammatory drugs, whereas cardiovascular anomalies are common side effects of COX-2 inhibitors and they have raised serious concerns. Therefore, inadequate assessment and pain management have become public health issues. ${ }^{10}$

Phytocompounds, used in herbal medicine for pain reduction, have gained significant attention. Herbal medicine, which is rooted in indigenous medical practices, has accumulated a great number of refined drugs through many generations of valuable experience. Extensive research shows that most herbal medicines have been used to manage pain with minimal or no side effects. ${ }^{11-15}$ A previous evaluation reported that lipoic acid, curcumin phytosome and piperine are effective complementary therapy for complimenting conventional treatments to achieve better efficacy in reducing neuropathic pain. ${ }^{16}$ A prospective clinical trial suggested that a Chinese herbal decoction (Xiaozhi decoction) effectively relieves postoperative pain and reduces analgesic medication after hemorrhoidectomy. ${ }^{17}$ Recent evidence suggests that the crude methanolic root extract of C. ficifolius showed anti-nociceptive and anti-inflammatory activities. ${ }^{18}$ Another study reports that incarvillateine (INCA), derived from the Chinese herb Incarvillea sinensis, shows potent nonopioid antinociceptive action mediated predominantly through A3AR - adenosine 3 receptor action. ${ }^{19}$

Bibliometrics is a quantitative analysis method that utilizes scientific literature to identify intellectual structures, active topics and emerging trends of a specific domain. ${ }^{20}$ This study used a bibliometric approach to track the advances in collective knowledge of herbal medicine for pain management with promising results that present an objective and comprehensive overall picture of research outputs and identify new perspectives on potential collaborations in this field. In this study, existing achievements of herbal medicine for pain were explored. Studies related to herbal medicine for pain published from 1990 to 2019 were retrieved from the Web of Science Core Collection (WoSCC), using the topic search. CiteSpace $^{21-23}$ and HistCite ${ }^{24,25}$ are information visualization softwares that are widely used to visualize and process bibliographic catalogs. Various types of indicators and multiple bibliometric methods were used to assess performance and other characteristics, including countries, institutions, authors, journals, research areas, references and keywords. In addition, bibliometric analysis was used for identification of international collaborations, intellectual structure, evolution of active topics, emerging trends, and research frontiers. To the best of our knowledge, this is the first study to conduct a comprehensive and systematic bibliometric analysis of herbal medicine for pain. The findings of this study provided a framework for the future development of research on herbal medicine for pain, which may help researchers explore new directions for future research and identify new perspectives on potential collaborations in this field.

\section{Materials and Methods Data Collection}

Data on herbal medicine for pain were searched by topic using the search strategy: $\mathrm{TS}=(($ herbal medicine OR traditional medicine OR herbal therapy OR herb therapy OR phytotherapy) AND (pain)). Studies published between 1990 and 2019 were retrieved to explore the global research trends in herbal medicine for pain. Results were restricted to studies published in English. After retrieval, only original articles were chosen for further investigation. A total of 2986 original articles were included. Data used in this study were lastly updated on December 31, 2020. Flow chart of the study retrieval strategy is presented in Figure 1.

\section{Bibliometrics Methods and Analysis Tools}

Historian's description of the progress of science is limited by their own experience, memory, and adequacy of available documentation. Subjective judgment primarily determines the historical picture of development of events. ${ }^{27}$ Traditional reviews are based on opinions of scholars, whereas bibliometric analysis focuses on finding qualitative changes in the quantity of references. ${ }^{27}$ In this paper, 


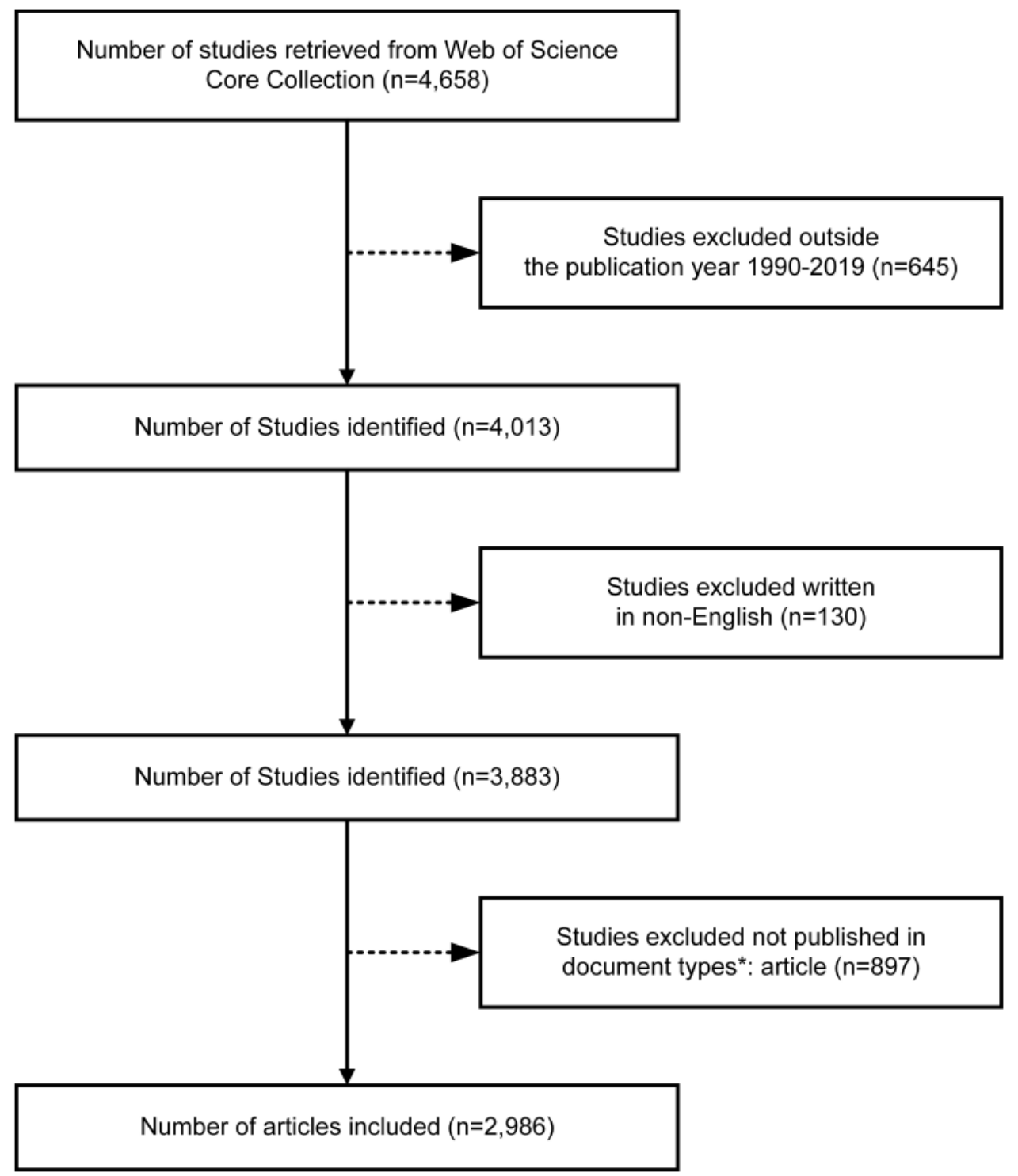

Figure I Flow chart of study retrieval and selection process.

Notes: *Reviews, editorial materials, corrections, reprints, meeting abstracts, early accesses, book chapters, proceedings papers and letters were excluded from the results.

bibliometric methods were used to explore existing achievements of herbal medicine for pain. CiteSpace (version 5.7 R2) ${ }^{21-23}$ and HistCite (version 8.12.16) (24,25 $^{24}$ softwares were used to assess bibliographic catalogs. Descriptive indicators (publications per year, research areas, journals and authors), qualitative indicators (bursts, betweenness centralities and citation scores) and relational indicators (collaborations of countries/regions and institutions) were used to assess bibliographic catalogs. Multiple bibliometric methods, such as co-citation analysis, cooccurrence analysis, and typical cluster analysis were performed to identify international collaborations, intellectual structure, evolution of active topics, emerging trends and research frontiers.

\section{Results and Discussion} Analysis of Publication Outputs

A total of 2986 original articles, which met the inclusion criteria, were included in this research. The articles were published in 1010 journals between 1990 and 2019 and comprised 112,788 references. After removing the duplicates, a total of 90,537 references were obtained. Total local citation score (TLCS) and total global citation score (TGCS) for all publications were 1503 and 
51,112. The H-index was 80 with 17.12 average citations per item. The number of total publications and citations by year is shown in Figure 2. The number of international scientific papers and citations on research on herbal medicine for pain from 1990 showed a gradual upward trend.

\section{International Collaborations of Countries/Regions}

Analysis of international collaborations of countries/ regions showed that a total of 113 countries/regions performed research in this field. Geographical distribution of publications on herbal medicine for pain research from countries/regions is presented in Figure 3.

Nearly half of the 2986 publications were from the top three countries. China had the highest number of publications $(685,22.9 \%)$, followed by the United States (584, $19.6 \%)$, and South Korea (260, 8.7\%). Co-occurrence network analysis was used to describe the relationship among various items based on the relations among the network nodes that are involved in information or connections travel. The network was used to assess the significance and impact of a node by determining the citation and centrality. Betweenness centrality is identified within a network's connectivity and represents the degree to which nodes stand between each other. International collaborations network between the most productive countries/regions is presented in Figure 4. Analysis of the collaboration network showed that Germany (0.34), the United States (0.16), China (0.14), and England (0.14) played the most active role and maintained collaborations with the remaining countries. Collaboration between China and Japan ranked first, followed by GermanyEngland and US-China. South Korea (0.03) and Iran (0.01) had a large number of publications but showed a lack of international collaborations. Details on cooperation network between the top 10 countries/regions are shown in Table 1.

China ranked first in publication production, whereas the United States had the highest number of citations both in TLCS and TGCS (Table 1). Despite England and Germany producing fewer publications, their total citation values were higher compared with several other highproducing countries, indicating that the publications were of high quality. The United States was second in number of outputs and value of centrality.

\section{Distribution of Institutions}

A total of 3488 institutions contributed to research in herbal medicine for pain reduction. The top 10 most productive and highest centrality institutions are shown in Table 2. Kyung Hee University (70, 2.3\%) from South Korea was the most productive institution, followed by China Academy of Chinese Medical Science (54, 1.8\%) and Shanghai University of Traditional Chinese Medicine (51, 1.7\%). Half of the top 10 most publishing institutions were from China. China institutions ranked first in terms of the total publications, indicating that Chinese scientists have explored this field more compared with researchers from other countries.

International collaborations among the most productive institutions are shown in Figure 5. University of

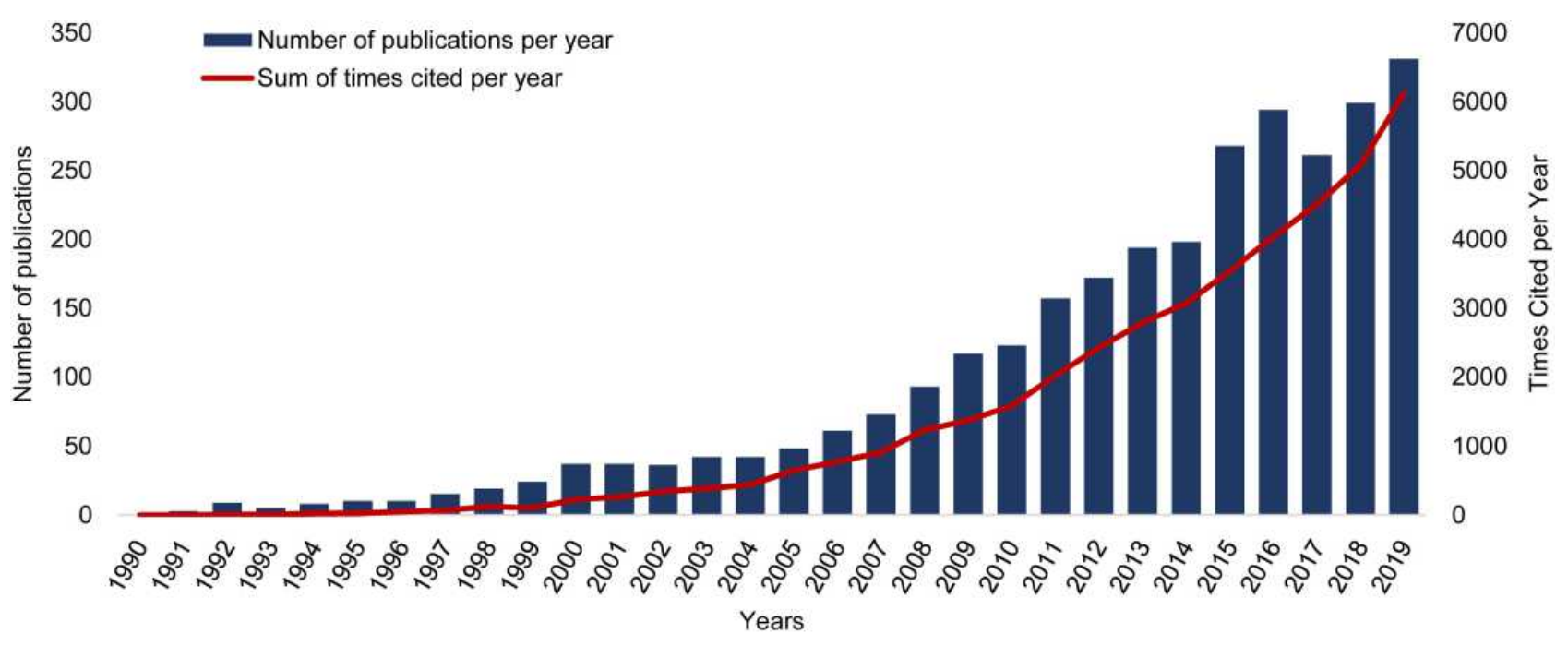

Figure 2 Number of total publications and citations by year. 


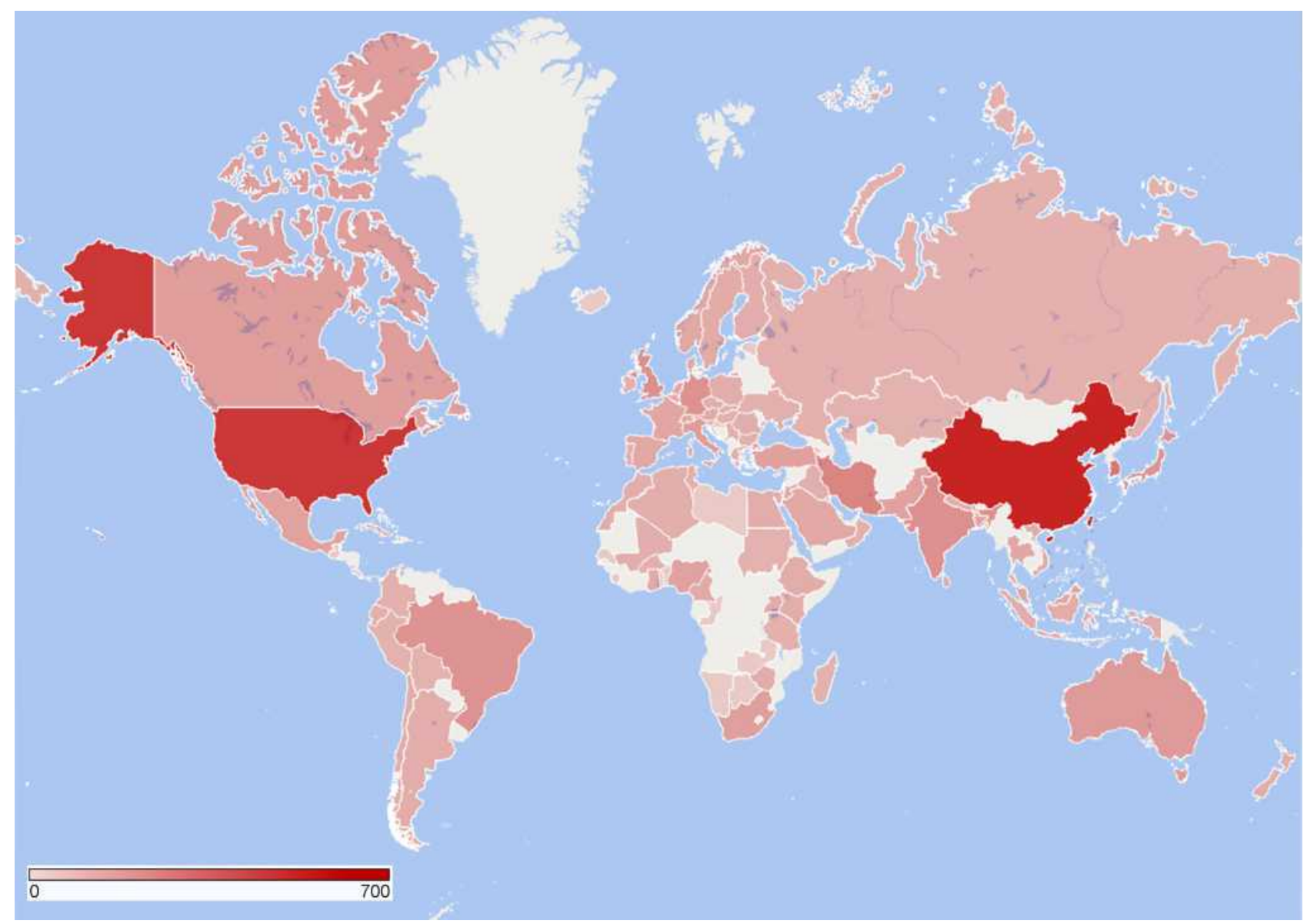

Figure 3 World map of countries/regions based on research on herbal medicine for pain.

Florida (0.56), University of Oulu (0.49) and Vanderbilt University (0.46) were the top three universities based on centrality. Notably, only one institution from the United States was among the top 10 most productive institutions. However, 6 out of top 10 most collaborative institutions were from the United States, indicating that United States institutions support collaboration in this field.

\section{Performance of Authors}

A total of 12,653 authors contributed to 2986 articles on herbal medicine for pain. The top 10 most productive and cited authors are presented in Table 3. Zhang Y was the most productive author, and contributed 24 articles, followed by Lee J (23), Lee JH (21) and Wang Y (21). However, the annual citation frequencies of the articles from these productive authors were not included. Sherman KJ (69) had the highest TLCS, indicating that he can be considered as the most important author in this field.
However, research by Vane JR (684) had the highest global influence.

\section{Characteristics of Journals}

Search results showed that research on herbal medicine for pain was published in 1011 journals. A dual-map overlay of journals that have published work related to herbal medicine for pain was generated by CiteSpace (Figure 6). Dual-map overlays were designed by Chen and Leydesdorff to explore patterns of scientific citation. ${ }^{28}$ The distribution of the base map of citing journals is shown on the left, representing the main disciplines (knowledge carriers) of herbal medicine for pain, and can be regarded as the application field (Figure 6). The right of the dual-map is the base map of cited journals corresponding to the distribution of cited journals, which represents the main disciplines cited (knowledge sources) (Figure 6). These can be regarded as the research basis of herbal medicine for pain.

Literature on herbal medicine for pain research is mainly represented in three major regions (Figure 6). The 


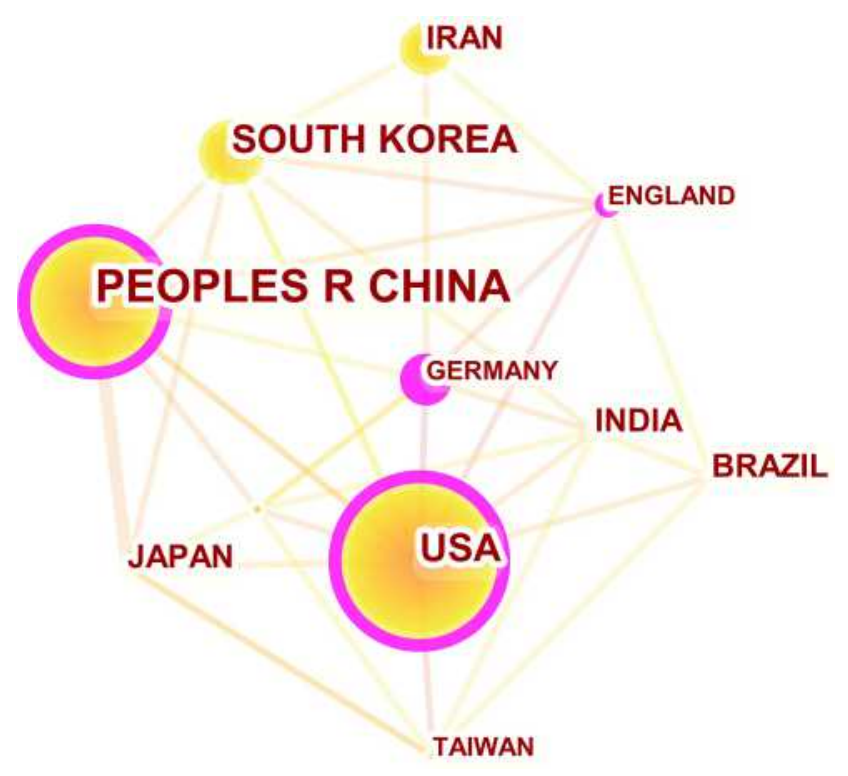

Figure 4 Collaboration network between countries/regions.

Notes: The size of the yellow circle represents the number of publications (the larger the circle, the more the publications). A bigger purple circle indicates a higher betweenness centrality. Thickness of the line between two nodes represents the strength of the collaboration.

three regions include, region in yellow at the edge of the upper part with the label of veterinary/animal/science; the region in orange with the label of molecular/biology/ immunology and the region in green with the label of

Table I Top 10 Countries/Regions with the Highest Number of Publications, Citation Score, and Centrality

\begin{tabular}{|l|l|l|l|l|l|}
\hline Ranking & $\begin{array}{l}\text { Countryl } \\
\text { Region }\end{array}$ & TP & TLCS & TGCS & Centrality \\
\hline 1 & $\begin{array}{l}\text { People's R } \\
\text { China }\end{array}$ & 685 & 302 & 8007 & 0.14 \\
\hline 2 & USA & 584 & 401 & 13,978 & 0.16 \\
\hline 3 & South Korea & 260 & 97 & 3194 & 0.03 \\
\hline 4 & Iran & 190 & 72 & 1796 & 0.01 \\
\hline 5 & India & 131 & 42 & 1522 & 0.07 \\
\hline 6 & Germany & 123 & 139 & 3623 & 0.34 \\
\hline 7 & Japan & 121 & 159 & 2312 & 0.01 \\
\hline 8 & Brazil & 121 & 74 & 1996 & 0.01 \\
\hline 9 & England & 111 & 83 & 4080 & 0.14 \\
\hline 10 & Taiwan & 95 & 29 & 1426 & 0.01 \\
\hline
\end{tabular}

Notes: Blue, green, orange and pink cells indicate the top three countries in each column.

Abbreviations: TP, total publications; TLCS, total local citation score; TGCS, total global citation score. medicine/medical/clinical. Major destination areas for citations with the biological origin include health/nursing/ medicine, molecular/biology/genetics and environmental/ toxicology/nutrition.

Top 10 most productive journals and research domains of each journal are listed in Table 4. A total of 296 articles were published in the Journal of Ethnopharmacology (IF 3.69), followed by Evidence-Based Complementary and Alternative Medicine (IF 1.813) with 117 articles and Journal of Alternative and Complementary Medicine (IF 2.256) with 84 articles. Analysis of Journal Citation Reports (JCR) from the WoS website showed that 7 of the top 10 journals were associated with the research domain of Integrative and Complementary Medicine and were the most active in areas for research on herbal medicine for pain.

\section{Evolution of Research Areas}

Evolution of research areas reveals the variation trends of various domains over time indicating the history and future of herbal medicine for pain research. Research areas in this study were defined by categories from the WoS website. Research on herbal medicine for pain has significantly advanced in the past 30 years and is currently broadly distributed in multiple research areas. Growth trends of the top 10 research areas are presented in Figure 7. The number of articles was very limited in every research area in the initial stage. Topics on General \& Internal Medicine and Neurosciences Neurology were relatively prominent in the mid-1990s and show steady increase in number over the past two decades. However, Integrative and Complementary Medicine and Pharmacology \& Pharmacy fields, which started in the mid1990s, rapidly expanded at the end of the twentieth century and had an upsurge in the late 2000s. Over the past 20 years, the top two leading productive areas were occupied by Pharmacology $\&$ Pharmacy and Integrative and Complementary Medicine. At the beginning of the twenty-first century, the number of plant science publications began to increase, and declined slightly at the end of the 2000s, but has increased significantly in recent years. Research and Experimental Medicine area became obvious in the late 2000s and showed steady growth. Number of articles in Oncology and Health Care Sciences Services research has gradually increased. Chemistry and Biochemistry and Molecular Biology areas have significant increase in recent years, based on the number of published articles. However, they show slow growth rate in the number of articles in the past two decades. 
Table 2 Top 10 Most Productive and Active Institutions

\begin{tabular}{|l|l|l|l|l|l|l|}
\hline Ranking & Count & Institutions & Country & Centrality & Institutions & Country \\
\hline 1 & 70 & Kyung Hee Univ & South Korea & 0.56 & Univ Florida & USA \\
\hline 2 & 54 & China Acad Chinese Med Sci & China & 0.49 & Univ Oulu & Finland \\
\hline 3 & 51 & Shanghai Univ Tradit Chinese Med & China & 0.46 & Vanderbilt Univ & USA \\
\hline 4 & 45 & Korea Inst Oriental Med & South Korea & 0.45 & Univ Washington & USA \\
\hline 5 & 45 & Univ Tehran Med Sci & Iran & 0.45 & Tech Univ Munich & Germany \\
\hline 6 & 39 & Beijing Univ Chinese Med & China & 0.44 & Karolinska Inst & Sweden \\
\hline 7 & 39 & China Med Univ & TAIWAN (China) & 0.44 & Kaiser Permanente Ctr HIth Res & USA \\
\hline 8 & 37 & Shahid Beheshti Univ Med Sci & Iran & 0.32 & Univ Milan & Italy \\
\hline 9 & 35 & Chinese Acad Sci & China & 0.30 & Univ Vermont & USA \\
\hline 10 & 35 & Univ Washington & USA & 0.26 & Washington Univ & USA \\
\hline
\end{tabular}

Abbreviations: Kyung Hee Univ, Kyung Hee University; China Acad Chinese Med Sci, China Academy of Chinese Medical Sciences; Shanghai Univ Tradit Chinese Med, Shanghai University of Traditional Chinese Medicine; Korea Inst Oriental Med, Korea Institute of Oriental Medicine; Univ Tehran Med Sci, Tehran University of Medical Sciences; Beijing Univ Chinese Med, Beijing University of Chinese Medicine; China Med Univ, China Medical University; Shahid Beheshti Univ Med Sci, Shahid Beheshti University of Medical Sciences; Chinese Acad Sci, Chinese Academy of Sciences; Univ Washington, University of Washington; Univ Florida, University of Florida; Univ Oulu, University of Oulu; Vanderbilt Univ, Vanderbilt University; Tech Univ Munich, Technical University of Munich; Karolinska Inst, Karolinska Institute; Kaiser Permanente Ctr Hlth Res, Kaiser Permanente Center for Health Research; Univ Milan, University of Milan; Univ Vermont, University of Vermont; Washington Univ, Washington University in St. Louis.

\section{Intellectual Structure}

Structural and temporal dynamics can be identified by most active topical areas and cited references. ${ }^{29} \mathrm{~A}$ cocitation network of references representing the evolution of the topics between 1990 and 2019 is shown in Figure 8.

History of research on herbal medicine for pain can be divided into three major phases of activities based on the overall structural and temporal dynamics of articles presented in Figure 8, as follows:

- Phase I (1990-1999): the initial stage, during which research output on herbal medicine for pain increased slowly (as shown in Figure 2). The upper part of the network with links shown in purple, and corresponding co-citations made in the first 10 years of the period between 1990 and 2019 are shown in Figure 8A. The entire network was divided into several clusters. Each cluster is a group of closely coupled documents, representing a distinct specialty or a thematic concentration in the field. The labels from the clustering are shown in Figure 8B.

- Phase II (2000-2009): the stage of smooth growth, during which research output on herbal medicine for pain and citations increased at a steady rate. Figure $8 \mathrm{~A}$ shows the central part of the network with links in orange, which are co-citations mostly made in the next 10 years, that is, the period between 2000 and 2009.

- Phase III (2010-2019): Figure 8A shows the lower part of the network with co-citation links in yellow, which implies that these co-citations were made in the most recent 10 years, that is, between 2010 and 2019. The period of development during which herbal medicine for pain research output increased rapidly. Recent developments are represented by this part of the network.

Common keywords and the most cited articles are regularly used to show the most significant logical areas of interest inside a particular subject of exploration. The top 10 most cited articles for each phase are listed in Table 5, which also shows the main research themes in each phase. The main information is summarized based on the bibliometric results from HistCite.

Phase I focused on the most cited references on the prevalence and patterns of use of herbal medicine ${ }^{33,36}$ (Table 5). The National Center for Complementary and Alternative Medicine (NCCAM) defines herbal medicine as an alternative, or complementary, prevention and treatment strategy. ${ }^{60}$ A survey reported that $37 \%$ of 143 advanced cancer patients used complementary 


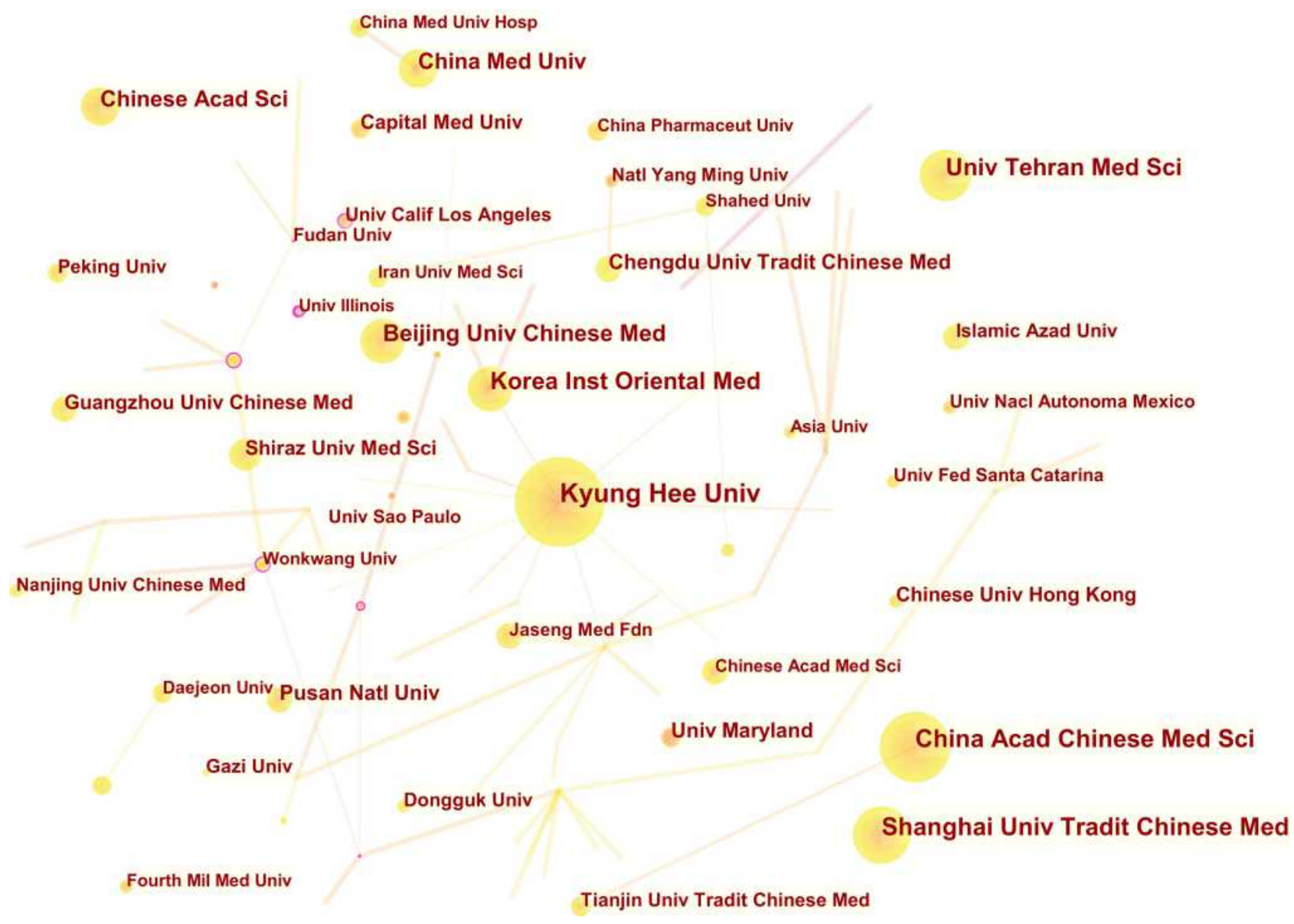

Figure 5 Collaboration networks of the institutions.

medications, and $39.6 \%$ of 197 complementary medications purchased were herbs. ${ }^{35}$ Moreover, assessments of prevalence and extent of use of herbal medicine were conducted among patients with gastrointestinal disorders, chronic arthritis, cancer and congestive heart failure, where pain is a common comorbid condition. ${ }^{31,32,35,39}$

Table 3 Top 10 Most Productive and Cited Authors

\begin{tabular}{|l|c|l|c|l|l|l|}
\hline Ranking & Record & Authors & TLCS & Author & TGCS & Author \\
\hline I & 24 & Zhang Y & 69 & Sherman KJ & 684 & Vane JR \\
\hline 2 & 23 & Lee J & 60 & Lao LX & 655 & Ahmad AMA \\
\hline 3 & 21 & Lee JH & 54 & Cherkin DC & 655 & Browall M \\
\hline 4 & 21 & Wang Y & 50 & Berman B & 655 & Bruyns I \\
\hline 5 & 20 & Ha IH & 40 & Handwerger B & 655 & Fernandez-Ortega P \\
\hline 6 & 19 & Lee MS & 40 & Zhang GG & 655 & Gudmundsdottir G \\
\hline 7 & 18 & Kamalinejad M & 36 & Molsberger A & 655 & Hummerston S \\
\hline 8 & 18 & Li J & 35 & Bausell B & 655 & Kearney N \\
\hline 9 & 17 & Van Staden J & 35 & Hogeboom CJ & 655 & Madsen E \\
\hline 10 & 16 & Kim MR & 33 & Maier C & 655 & Magri M \\
\hline
\end{tabular}




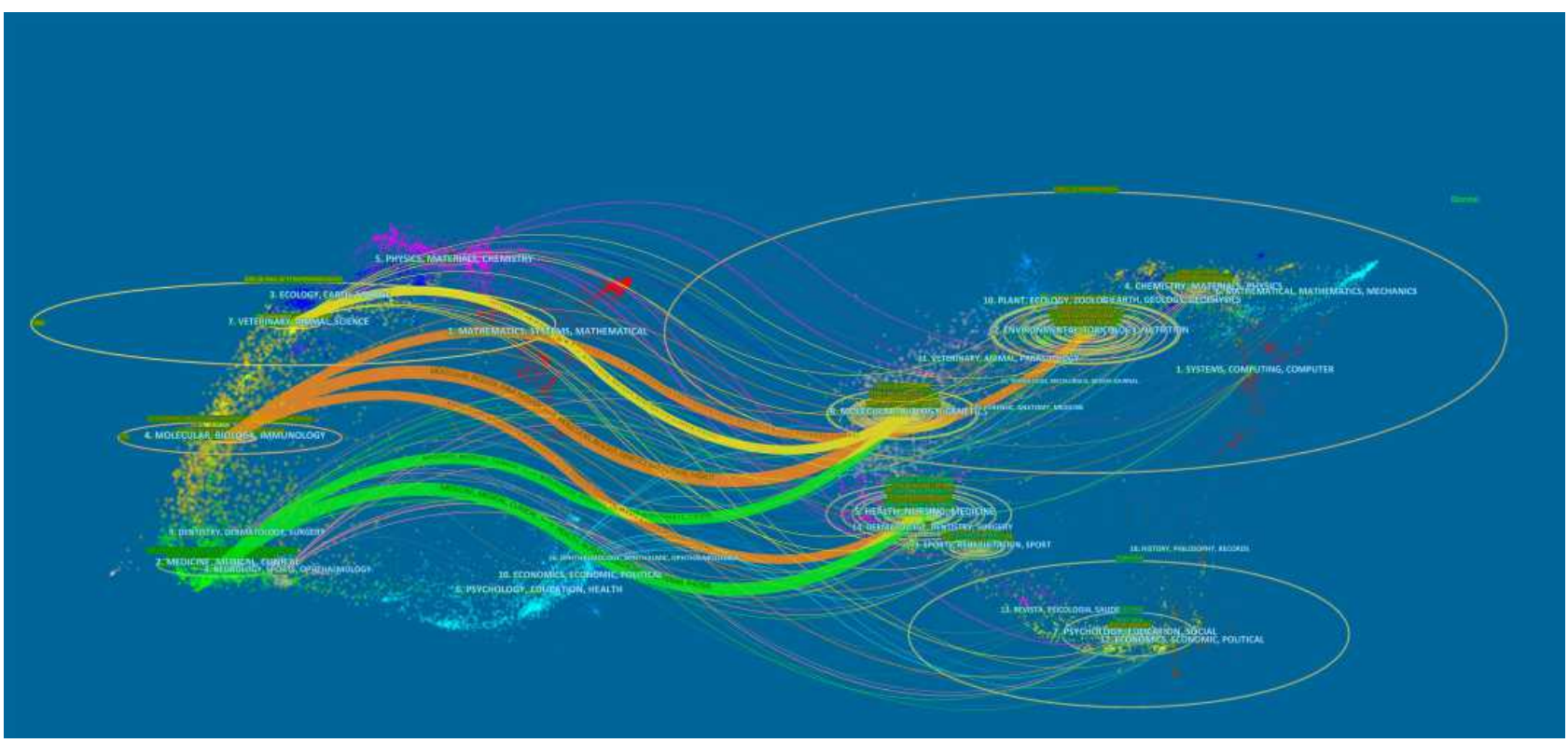

Figure 6 Dual-map overlay of journals related to studies on herbal medicine for pain.

Another major research theme in phase I was analgesic effect and mechanism of herbal medicine. ${ }^{38}$ A study revealed that the anti-inflammatory and analgesic constituents from the roots of Angelica pubescens were related to peripheral inhibition of inflammatory substances and to the influence on the central nervous system. ${ }^{30}$ Wei

Table 4 Top 10 Most Productive Journals and Research Domain of Each Journal

\begin{tabular}{|c|c|c|c|c|c|c|c|}
\hline Rank & Source Titles & Records & TLCS & TGCS & Country & IF $2019 *$ & Research Domain \\
\hline I & Journal of Ethnopharmacology & 296 & 281 & 7407 & Ireland & 3.69 & $\begin{array}{l}\text { Plant Sciences, Pharmacology and Pharmacy, } \\
\text { Integrative and Complementary Medicine }\end{array}$ \\
\hline 2 & $\begin{array}{l}\text { Evidence-Based } \\
\text { Complementary and } \\
\text { Alternative Medicine }\end{array}$ & 117 & 17 & 1051 & England & 1.813 & Integrative and Complementary Medicine \\
\hline 3 & $\begin{array}{l}\text { Journal of Alternative and } \\
\text { Complementary Medicine }\end{array}$ & 84 & 110 & 1463 & USA & 2.256 & Integrative and Complementary Medicine \\
\hline 4 & $\begin{array}{l}\text { BMC Complementary and } \\
\text { Alternative Medicine }\end{array}$ & 72 & 0 & 1098 & England & 2.833 & Integrative and Complementary Medicine \\
\hline 5 & Trials & 49 & 0 & 282 & England & 1.883 & Research and Experimental Medicine \\
\hline 6 & $\begin{array}{l}\text { Complementary Therapies in } \\
\text { Medicine }\end{array}$ & 47 & 86 & 809 & Scotland & 2.063 & Integrative and Complementary Medicine \\
\hline 7 & Pharmaceutical Biology & 34 & 16 & 402 & England & 2.971 & $\begin{array}{l}\text { Plant Sciences, Medical Laboratory Technology, } \\
\text { Pharmacology and Pharmacy }\end{array}$ \\
\hline 8 & Phytotherapy Research & 34 & 24 & 936 & USA & 4.087 & Pharmacology and Pharmacy \\
\hline 9 & Phytomedicine & 33 & 23 & 536 & Germany & 4.268 & $\begin{array}{l}\text { Plant Sciences, Pharmacology and Pharmacy, } \\
\text { Integrative and Complementary Medicine }\end{array}$ \\
\hline 10 & $\begin{array}{l}\text { American Journal of Chinese } \\
\text { Medicine }\end{array}$ & 28 & 35 & 513 & Singapore & 3.682 & $\begin{array}{l}\text { Integrative and Complementary Medicine, } \\
\text { General and Internal Medicine }\end{array}$ \\
\hline
\end{tabular}

Note: *Data from the 2019 edition of Journal Citation Reports. 


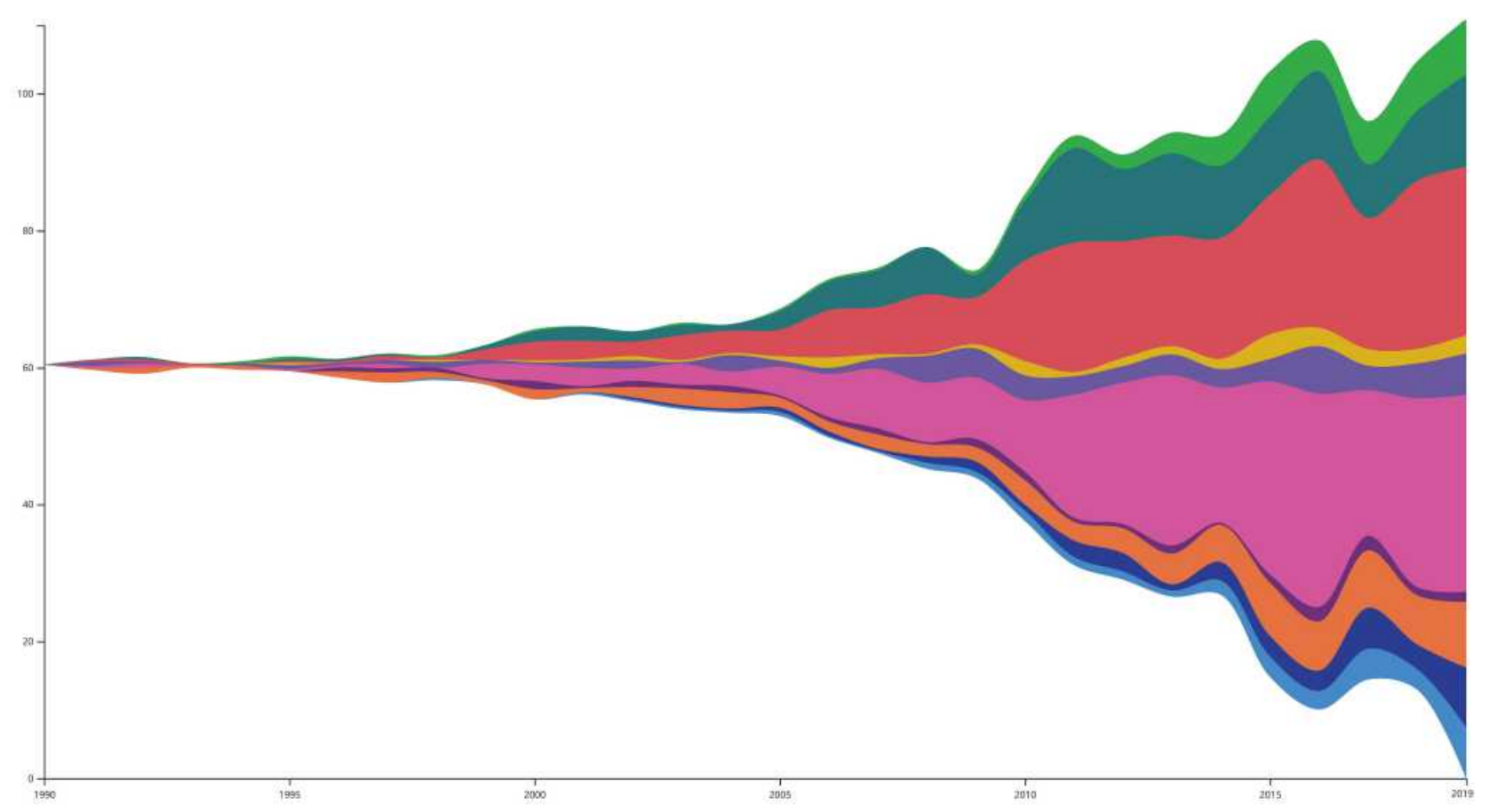

-Biochemistry Molecular Bialogy Chemistry General Internal Medicine $\bullet$ Health Care Sciences Services integrative Complement

- Neurosciences Neurology O Oncology Pharmacology Pharmacy Plant Sciences Research Experimental Medicine

Figure 7 Steam graph of the top 10 research areas.

et al conducted a study to evaluate the effects of herbal medicine extracts of Duhuo (Radix Angelicae Pubescentis), Bai Jiang cao (Patriniae Herba cum Radice), Yan hu suo (Rhizoma Corydalis) and Sanqui (Panax Notoginseng) on a rat model of inflammatory hyperalgesia. The results supported that some herbal agents may provide an alternative approach to the treatment of persistent inflammatory pain and hyperalgesia. ${ }^{37}$ Vaz's study suggested that, despite that the mechanisms underlying the antinociception caused by extract of herbal medicine Catuama were still not completely understood, the herbal medicine Catuama may constitute a useful

\section{A}

B

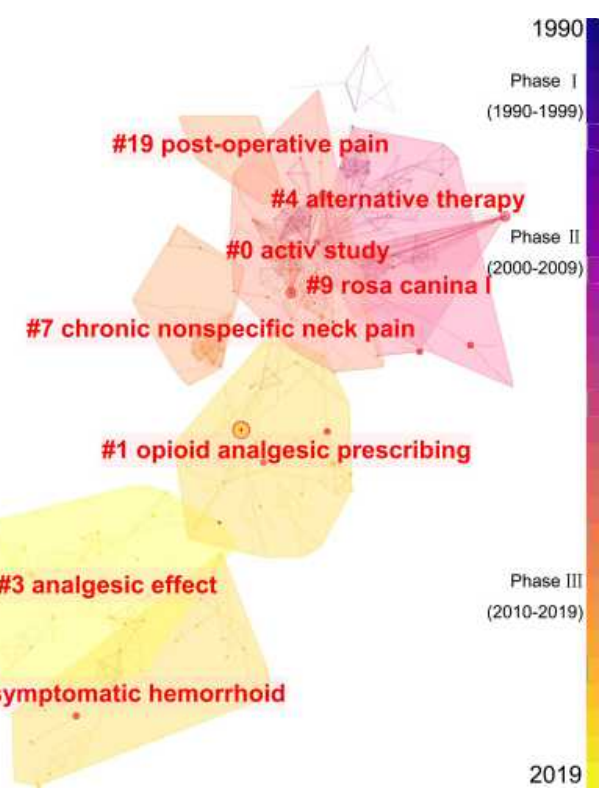

Figure 8 Characteristics of intellectual structure. (A) A network of co-cited references about research on herbal medicine for pain. (B) Cluster view of co-cited references from publications between 1990 and 2019. 
Table 5 The 10 Most Cited References in Each Phase

\begin{tabular}{|c|c|c|c|}
\hline $\begin{array}{l}\text { First } \\
\text { author }\end{array}$ & Year & Title & Journal \\
\hline \multicolumn{4}{|c|}{ Phase I (1990-1999) } \\
\hline $\mathrm{Chen}^{30}$ & 1995 & Anti-inflammatory and analgesic activities from roots of Angelica pubescens & Planta Medica \\
\hline Heinrich ${ }^{31}$ & 1992 & $\begin{array}{l}\text { Indigenous phytotherapy of gastrointestinal disorders in a lowland Mixe community } \\
\text { (Oaxaca, Mexico): ethnopharmacologic evaluation }\end{array}$ & Journal of Ethnopharmacology \\
\hline Mills ${ }^{32}$ & 1996 & $\begin{array}{l}\text { Effect of a proprietary herbal medicine on the relief of chronic arthritic pain: a double- } \\
\text { blind study }\end{array}$ & British Journal of Rheumatology \\
\hline Elder $^{33}$ & 1997 & Use of alternative health care by family practice patients & Archives of Family Medicine \\
\hline $\mathrm{Vaz}^{34}$ & 1997 & $\begin{array}{l}\text { Analgesic effect of the herbal medicine Catuama in thermal and chemical models of } \\
\text { nociception in mice }\end{array}$ & Phytotherapy Research \\
\hline Oneschuk $^{35}$ & 1998 & $\begin{array}{l}\text { The use of complementary medications by cancer patients attending an outpatient pain } \\
\text { and symptom clinic }\end{array}$ & Journal of Palliative Care \\
\hline Gordon $^{36}$ & 1998 & $\begin{array}{l}\text { Use of and interest in alternative therapies among adult primary care clinicians and adult } \\
\text { members in a large health maintenance organization }\end{array}$ & Western Journal of Medicine \\
\hline $\mathrm{Wei}^{37}$ & 1999 & Effects of four herbal extracts on adjuvant-induced inflammation and hyperalgesia in rats & $\begin{array}{l}\text { Journal of Alternative and } \\
\text { Complementary Medicine }\end{array}$ \\
\hline Mogil $^{38}$ & 1998 & Ginsenoside Rf, a trace component of ginseng root, produces antinociception in mice & Brain Research \\
\hline Ackman $^{39}$ & 1999 & Use of nonprescription medications by patients with congestive heart failure & Annals of Pharmacotherapy \\
\hline \multicolumn{4}{|c|}{ Phase II (2000-2009) } \\
\hline Zhang $^{40}$ & 2004 & $\begin{array}{l}\text { The variability of TCM pattern diagnosis and herbal prescription on rheumatoid arthritis } \\
\text { patients }\end{array}$ & $\begin{array}{l}\text { Alternative Therapies in Health } \\
\text { and Medicine }\end{array}$ \\
\hline Chrubasik $^{41}$ & 2000 & $\begin{array}{l}\text { Treatment of low back pain exacerbations with willow bark extract: a randomized double- } \\
\text { blind study }\end{array}$ & American Journal of Medicine \\
\hline Bliddal $^{42}$ & 2000 & $\begin{array}{l}\text { A randomized, placebo-controlled, cross-over study of ginger extracts and ibuprofen in } \\
\text { osteoarthritis }\end{array}$ & Osteoarthritis and Cartilage \\
\hline Zhang $^{43}$ & 2005 & $\begin{array}{l}\text { Variability in the Traditional Chinese Medicine (TCM) diagnoses and herbal prescriptions } \\
\text { provided by three TCM practitioners for } 40 \text { patients with rheumatoid arthritis }\end{array}$ & $\begin{array}{l}\text { Journal of Alternative and } \\
\text { Complementary Medicine }\end{array}$ \\
\hline $\mathrm{Xu}^{44}$ & 2006 & Pain-relieving effects of processed Aconiti tuber in $\mathrm{CCl}$-neuropathic rats & Journal of Ethnopharmacology \\
\hline Bensoussan $^{45}$ & 2000 & Risks associated with the practice of traditional Chinese medicine - an Australian study & Archives of Family Medicine \\
\hline Michalsen ${ }^{46}$ & 2003 & Effectiveness of leech therapy in osteoarthritis of the knee - a randomized, controlled trial & Annals of Internal Medicine \\
\hline Hinoshita $^{47}$ & 2003 & $\begin{array}{l}\text { Effect of orally administered Shao-Yao-Gan-Cao-Tang (Shakuyaku-kanzo-to) on muscle } \\
\text { cramps in maintenance hemodialysis patients: A preliminary study }\end{array}$ & $\begin{array}{l}\text { American Journal of Chinese } \\
\text { Medicine }\end{array}$ \\
\hline Molassiotis $^{48}$ & 2005 & Use of complementary and alternative medicine in cancer patients: a European survey & Annals of Oncology \\
\hline Walker ${ }^{49}$ & 2008 & Antinociceptive activity of Mirabilis jalapa in mice & Journal of Ethnopharmacology \\
\hline \multicolumn{4}{|c|}{ Phase III (2010-20I9) } \\
\hline Park JJ $J^{50}$ & 2010 & Integrative package for low back pain with leg pain in Korea: a prospective cohort study & $\begin{array}{l}\text { Complementary Therapies in } \\
\text { Medicine }\end{array}$ \\
\hline
\end{tabular}


Table 5 (Continued).

\begin{tabular}{|c|c|c|c|}
\hline $\begin{array}{l}\text { First } \\
\text { author }\end{array}$ & Year & Title & Journal \\
\hline Kanodia $^{51}$ & 2010 & $\begin{array}{l}\text { Perceived benefit of complementary and alternative medicine (CAM) for back pain: } \\
\text { a national survey }\end{array}$ & $\begin{array}{l}\text { Journal of the American Board } \\
\text { of Family Medicine }\end{array}$ \\
\hline Ishola ${ }^{52}$ & 2011 & $\begin{array}{l}\text { Analgesic and anti-inflammatory activities of Cnestis ferruginea Vahl ex DC (Connaraceae) } \\
\text { methanolic root extract }\end{array}$ & Journal of Ethnopharmacology \\
\hline Park $^{53}$ & 2013 & $\begin{array}{l}\text { A prospective, randomized, double-blind, multicenter comparative study on the safety and } \\
\text { efficacy of Celecoxib and GCSB-5, dried extracts of six herbs, for the treatment of } \\
\text { osteoarthritis of knee joint }\end{array}$ & Journal of Ethnopharmacology \\
\hline $\mathrm{Xu}^{54}$ & 2012 & $\begin{array}{l}\text { Role of puerarin in the signalling of neuropathic pain mediated by } \mathrm{P} 2 \mathrm{X}(3) \text { receptor of } \\
\text { dorsal root ganglion neurons }\end{array}$ & Brain Research Bulletin \\
\hline Rodrigues $^{55}$ & 2012 & $\begin{array}{l}\text { Antinociceptive and anti-inflammatory potential of extract and isolated compounds from } \\
\text { the leaves of Salvia officinalis in mice }\end{array}$ & Journal of Ethnopharmacology \\
\hline $\mathrm{Gao}^{56}$ & 2013 & Analgesic effect of sinomenine in rodents after inflammation and nerve injury & $\begin{array}{l}\text { European Journal of } \\
\text { Pharmacology }\end{array}$ \\
\hline $\mathrm{Li}^{57}$ & 2011 & $\begin{array}{l}\text { Analgesic effect and mechanism of the three TCM-herbal drug-combination Tou Feng Yu } \\
\text { Pill on treatment of migraine }\end{array}$ & Phytomedicine \\
\hline Chopra ${ }^{58}$ & 2013 & $\begin{array}{l}\text { Ayurvedic medicine offers a good alternative to glucosamine and celecoxib in the } \\
\text { treatment of symptomatic knee osteoarthritis: a randomized, double-blind, controlled } \\
\text { equivalence drug trial }\end{array}$ & Rheumatology \\
\hline $\mathrm{Xu}^{59}$ & 2013 & $\begin{array}{l}\text { Pharmacokinetic comparisons of two different combinations of Shaoyao-Gancao } \\
\text { Decoction in rats: competing mechanisms between paeoniflorin and glycyrrhetinic acid }\end{array}$ & Journal of Ethnopharmacology \\
\hline
\end{tabular}

therapeutic agent for the treatment of clinical pain. ${ }^{34}$ These findings indicated that herbal medicine was regarded as a complementary and alternative medicine for pain and appeared to be gaining popularity among patients with pain in the early stage of research.

Studies in Phase II were a continuation and extension of phase I research. For example, a survey conducted by Molassiotis et al explored the use of complementary and alternative medicine (CAM) in 956 cancer patients from 14 European countries. ${ }^{48}$ Data results suggested that CAM was popular among cancer patients with 35.9\% using some form of CAM, and herbal medicines and remedies were the most commonly used therapies. In addition, clinical research was another major research focus in Phase II. Chrubasik et al conducted a study to evaluate the effectiveness of Willow (Salix) bark extract for the treatment of low back pain. Clinical data from their research suggested that Willow bark extract may be a useful and safe treatment for low back pain. ${ }^{41}$ Similar studies were conducted to examine the effect of ginger extract on patients with chronic pain due to osteoarthritis and to evaluate the effectiveness of leech therapy for symptomatic relief of osteoarthritis of the knee. ${ }^{42,46}$ Another preliminary study revealed that the traditional herbal medicine, Shao-yaogan-cao-tang, could prevent frequent and unendurable muscle cramps in patients undergoing hemodialysis. These studies demonstrated that scholars are placing significant attention on the clinical evidence of herbal medicine.

Analysis of the third stage (2010-2019) showed significant increase in the number of articles published. Therefore, the research topic was summarized based on the top 10 most cited publications in this stage. In Phase III, scholars became increasingly concerned about analgesic effect and mechanism of herbal medicine, particularly traditional medicine. Cnestis ferruginea is a shrub widely used in traditional African Medicine (TAM) for the treatment of various painful and inflammatory conditions. An experimental result showed that Cnestis ferruginea exerts its analgesic effect possibly mediated through peripheral and central mechanisms involving inhibition of release and actions of vasoactive substances and prostaglandins. ${ }^{52}$ 
Salvia officinalis L. has been used as a traditional herbal medicine for gastric disturbances and inflammatory processes. An experiment reported that carnosol and ursolic acid/oleanolic acid contained in Salvia officinalis appears to contribute to the antinociceptive property of the extract, possibly through a modulatory influence on TRPA1receptors. ${ }^{55}$ The studies were also carried out in a traditional Chinese herbal medicine, Ge-gen and Sinomenium acutum, and well-known traditional Chinese medicine prescriptions, Shaoyao-Gancao Decoction (SGD) and Tou Feng Yu pill (TFY). ${ }^{54,56,57,59}$ These findings provided additional pharmacological information and contributed to the further study. On the other hand, clinical evidence of herbal medicine for pain attained more attention. Two randomized controlled trials (RCT) were conducted to demonstrate clinical equivalence between herbal medicine and celecoxib (NSAID) for the treatment of knee osteoarthritis. The results of these studies supported that herbal formulations (especially GCSB-5 and SGCG) significantly reduced knee pain, and were comparable to Celecoxib in terms of the efficacy and safety for the treatment of osteoarthritis of knee joint. ${ }^{53,58}$ Moreover, a prospective cohort study involving patients with low back and leg pain was carried out in Korea. After 24 weeks of integrative therapy (including herbal medicines), patients reported improvements in all outcome measures. ${ }^{51}$

\section{Hotspots and Research Frontiers}

Burst patterns of keywords, that is, indexing terms, may reveal hotspots within a certain field in a certain period. The research fronts of the domain in each period can be detected through analysis of keywords with high burst rates. A stronger burst rate shows higher attention to the research topic and can effectively represent the research frontier in this period. The top 40 keywords with citation bursts are presented in Figure 9.

Based on the meaning of the items, 40 keywords with citation bursts were classified into four categories. "Alternative medicine" was the major keyword with high strength in citation burst in phase I (1990-1999) period (Figure 9). At the initial stage, the number of academic publications on herbal medicine for pain was rather scant and herbal medicine was recognized as the most common form of alternative medicine from its inception. Phase II (2000-2009) was an extension of phase I research and the most important keyword was "Asteraceae" belonging to the medicine category. Phase III (2010-2019) was a period of research domain transition from an embryonic stage to a fast-growing stage and varied widely in terms of keywords. Researchers originally focused on the mechanisms of action (such as "anti-inflammatory" and "antinociceptive"); however, keywords of pain-related diseases and disorders affecting high-attention have been considered since 2013. Keywords such as "knee osteoarthritis", "cancer", and "low back pain" are current citation bursts, indicating that they are research frontier diseases. Moreover, some keywords associated with the research on mechanisms of action, such as "inflammation", "antioxidant" and "cytokine", remain at the forefront of the herbal medicine for pain.

\section{Conclusion}

Substantial efforts have been invested in the search for alternative pain medications in the past few years. Research in the field of herbal medicine for pain has increased exponentially in the last decade; however, few bibliometric studies have been performed. This study sought to assess the global research trends of herbal medicine for pain from 1990 to 2019, using bibliometric methods. The findings of this study can be summarized as follows:

- China has the highest output, whereas publications from the United States are of the highest quality. China-Japan show the most active collaborations.

- Kyung Hee University from South Korea is the most productive institution. The total number of publications from Chinese institutions ranks first, whereas the United States institutions attach great importance to cooperation in this field.

- Zhang $\mathrm{Y}$ is the most productive author, whereas Sherman KJ and Vane JR have the greatest influence in the field.

- The most productive and cited source is the Journal of Ethnopharmacology, whereas Integrative and Complementary Medicine is the most active research area.

- Integrative and Complementary Medicine and Pharmacology Pharmacy are the two most broadly distributed areas in papers published in this particular field in recent 20 years. Plant Sciences, Chemistry, and Biochemistry Molecular Biology have shown a very high growth rate in recent years.

- The history of herbal medicine for pain research can be divided into three phases. In Phase I (1990-1999), the 


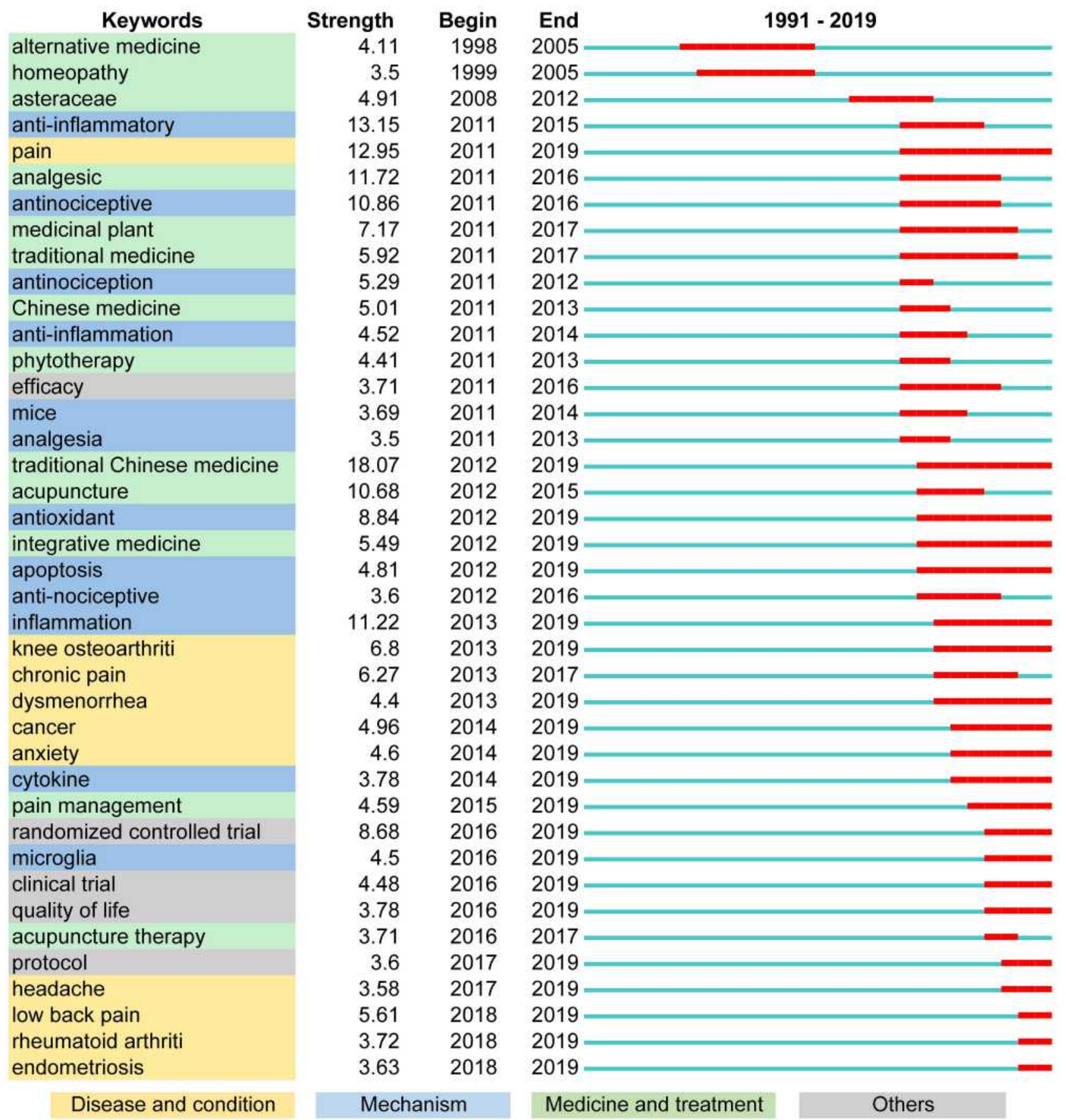

Figure 9 Top 40 keywords with citation bursts related to herbal medicine for pain from 1990 to 2019.

Notes: Time intervals are present as blue lines and the periods representing the burst keyword category are presented in red lines, indicating the beginning and end of the time interval of each burst.

publications focused mainly on prevalence and patterns of use of herbal medicine, whereas in Phase II (2000-2009), researchers paid significant attention to clinical evidence of herbal medicine for pain. In Phase III (2010-2019), there is a growing interest in analgesic effect and mechanism of herbal medicine. Clinical research on herbal medicine for pain remains one of the most vibrant areas of investigation within the field.

- Keywords such as "knee osteoarthritis", "cancer", and "low back pain" are current citation bursts, indicating that they are research frontier diseases. Moreover, some keywords associated with the 
research on mechanisms of action, such as "inflammation", "antioxidant" and "cytokine", remain at the forefront of the herbal medicine for pain.

In this paper, we aimed to assess the global research trends of herbal medicine for pain from 1990 to 2019, using bibliometric methods, and explored international collaborations, intellectual structure, evolution of active topics, emerging trends, and research frontiers. This paper lays a framework for future development of research on herbal medicine for pain. This information will help researchers explore new directions for future research and identify new perspectives on potential collaborations in this field. In addition, these findings have implications for policymakers and funding agencies.

\section{Disclosure}

Authors declare no conflicts of interest in this work.

\section{References}

1. Centers for Disease Control and Prevention. Wide-Ranging Online Data for Epidemiologic Research (WONDER). Atlanta: US Department of Health and Human Services; 2017.

2. Committee IPRC. National pain strategy report: a comprehensive population health-level strategy for pain; 2016. Available from: https://www.iprcc.nih.gov/national-pain-strategy-overview/nationalpain-strategy-report. Accessed December 12, 2020.

3. Dahlhamer J, Lucas J, Zelaya C, et al. Prevalence of chronic pain and high-impact chronic pain among adults-United States, 2016. Morbid Mortal Wkly Rep. 2018;67(36):1001. doi:10.15585/mmwr.mm6736a2

4. Gureje O, Von Korff M, Simon GE, Gater R. Persistent pain and well-being: a World Health Organization study in primary care. JAMA. 1998;280(2):147-151. doi:10.1001/jama.280.2.147

5. Gaskin DJ, Richard P. The economic costs of pain in the United States. J Pain. 2012;13(8):715-724. doi:10.1016/j.jpain.2012.03.009

6. Health UDo, Services H. Pain Management Best Practices InterAgency Task Force Report: Updates, Gaps, Inconsistencies, and Recommendations. Washington, DC: US Department of Health and Human Services; 2019.

7. Chou R. Five things to know when a psychiatric patient is prescribed opioids for pain. JAMA Psychiatry. 2020.

8. Centers for Disease C, Prevention. Vital signs: overdoses of prescription opioid pain relievers-United States, 1999-2008. MMWR 2011;60(43):1487-1492.

9. Hedegaard H, Miniño AM, Warner M. Drug overdose deaths in the United States, 1999-2018. NCHS Data Brief. 2020;(356):1-8.

10. Institute of Medicine Committee on Advancing Pain Research $C$, Education. The national academies collection: reports funded by National Institutes of Health. In: Relieving Pain in America: A Blueprint for Transforming Prevention, Care, Education, and Research. Washington (DC):National Academies Press (US); 2021.

11. Wirth JH, Hudgins JC, Paice JA. Use of herbal therapies to relieve pain: a review of efficacy and adverse effects. Pain Manag Nurs. 2005;6(4):145-167. doi:10.1016/j.pmn.2005.08.003

12. Arai Y-C, Makino I, Ikemoto T, et al. Kampo for the treatment of pain in Japan: a review. Pain Ther. 2020;9(1):161-170. doi:10.1007/ s40122-020-00160-w
13. Uritu CM, Mihai CT, Stanciu G-D, et al. Medicinal plants of the family Lamiaceae in pain therapy: a review. Pain Res Manage. 2018;2018:7801543. doi:10.1155/2018/7801543

14. Luo Y, Wang C-Z, Sawadogo R, Tan T, Yuan C-S. Effects of herbal medicines on pain management. Am J Chin Med. 2020;48(01):1-16. doi:10.1142/S0192415X20500019

15. Forouzanfar F, Hosseinzadeh H. Medicinal herbs in the treatment of neuropathic pain: a review. Iran J Basic Med Sci. 2018;21 (4):347-358. doi:10.22038/IJBMS.2018.24026.6021

16. Di Pierro F, Settembre R. Safety and efficacy of an add-on therapy with curcumin phytosome and piperine and/or lipoic acid in subjects with a diagnosis of peripheral neuropathy treated with dexibuprofen. $J$ Pain Res. 2013;6:497-503. doi:10.2147/JPR.S48432

17. Shen J, Luo X, Zhou X, et al. Xiaozhi decoction reduced posthemorrhoidectomy pain and analgesic medication consumption: a prospective study. J Pain Res. 2017;10:197. doi:10.2147/JPR. S128500

18. Demsie DG, Yimer EM, Berhe AH, Altaye BM, Berhe DF. Antinociceptive and anti-inflammatory activities of crude root extract and solvent fractions of Cucumis ficifolius in mice model. J Pain Res. 2019;12:1399. doi:10.2147/JPR.S193029

19. Priebe A, Hunke M, Tonello R, et al. Ferulic acid dimer as a non-opioid therapeutic for acute pain. J Pain Res. 2018;11:1075. doi:10.2147/JPR.S161161

20. Chen $\mathrm{C}, \mathrm{Hu} \mathrm{Z}$, Liu S, Tseng $\mathrm{H}$. Emerging trends in regenerative medicine: a scientometric analysis in CiteSpace. Expert Opin Biol Ther. 2012;12(5):593-608. doi:10.1517/14712598.2012.674507

21. Chen C. Searching for intellectual turning points: progressive knowledge domain visualization. Proc Natl Acad Sci U S A. 2004;101 (Suppl 1):5303-5310. doi:10.1073/pnas.0307513100

22. Chen C. CiteSpace II: detecting and visualizing emerging trends and transient patterns in scientific literature. J Am Soc Info Sci Technol. 2006;57(3):359-377. doi:10.1002/asi.20317

23. Chen C, Ibekwe-SanJuan F, Hou J. The structure and dynamics of cocitation clusters: a multiple-perspective cocitation analysis. $J \mathrm{Am}$ Soc Info Sci Technol. 2010;61(7):1386-1409. doi:10.1002/ asi.21309

24. Garfield E, Pudovkin AI, Istomin VS. Why do we need algorithmic historiography? J Am Soc Info Sci Technol. 2003;54(5):400-412. doi:10.1002/asi.10226

25. Garfield E. From the science of science to Scientometrics visualizing the history of science with HistCite software. J Informetr. 2009;3 (3):173-179. doi:10.1016/j.joi.2009.03.009

27. Garfield E, Sher IH, Torpie RJ. The use of citation data in writing the history of science. Inst Sci Info Inc. 1964.

28. Chen C, Leydesdorff L. Patterns of connections and movements in dualmap overlays: a new method of publication portfolio analysis. J Assoc Info Sci Technol. 2014;65(2):334-351. doi:10.1002/asi.22968

29. Chen C, Dubin R, Kim MC. Emerging trends and new developments in regenerative medicine: a scientometric update $(2000-2014)$. Expert Opin Biol Ther. 2014;14(9):1295-1317. doi:10.1517/ 14712598.2014.920813

30. Chen YF, Tsai HY, Wu TS. Anti-inflammatory and analgesic activities from roots of Angelica pubescens. Planta Med. 1995;61(1):2-8. doi:10.1055/s-2006-957987

31. Heinrich M, Rimpler H, Barrera NA. Indigenous phytotherapy of gastrointestinal disorders in a lowland Mixe community (Oaxaca, Mexico): ethnopharmacologic evaluation. $J$ Ethnopharmacol. 1992;36(1):63-80. doi:10.1016/0378-8741(92)90062-V

32. Mills SY, Jacoby RK, Chacksfield M, Willoughby M. Effect of a proprietary herbal medicine on the relief of chronic arthritic pain: a double-blind study. $B r \quad J$ Rheumatol. 1996;35(9):874-878. doi:10.1093/rheumatology/35.9.874

33. Elder NC, Gillcrist A, Minz R. Use of alternative health care by family practice patients. Arch Fam Med. 1997;6(2):181-184. doi:10.1001/archfami.6.2.181 
34. Vaz ZR, Mata LV, Calixto JB. Analgesic effect of the herbal medicine catuama in thermal and chemical models of nociception in mice. Phytotherapy Res. 1997;11(2):101-106. doi:10.1002/(SICI)10991573(199703)11:2<101::AID-PTR28>3.0.CO;2-U

35. Oneschuk D, Fennell L, Hanson J, Bruera E. The use of complementary medications by cancer patients attending an outpatient pain and symptom clinic. J Palliat Care. 1998;14(4):21-26. doi:10.1177/ 082585979801400404

36. Gordon NP, Sobel DS, Tarazona EZ. Use of and interest in alternative therapies among adult primary care clinicians and adult members in a large health maintenance organization. West J Med. 1998;169 (3):153-161.

37. Wei F, Zou S, Young A, Dubner R, Ren K. Effects of four herbal extracts on adjuvant-induced inflammation and hyperalgesia in rats. J Altern Complement Med. 1999;5(5):429-436. doi:10.1089/ acm.1999.5.429

38. Mogil JS, Shin YH, McCleskey EW, Kim SC, Nah SY. Ginsenoside $\mathrm{Rf}$, a trace component of ginseng root, produces antinociception in mice. Brain Res. 1998;792(2):218-228. doi:10.1016/S0006-8993(98) 00133-4

39. Ackman ML, Campbell JB, Buzak KA, et al. Use of nonprescription medications by patients with congestive heart failure. Ann Pharmacother. 1999;33(6):674-679. doi:10.1345/aph.18283

40. Zhang GG, Lao L, Bausell B, et al. The variability of TCM pattern diagnosis and herbal prescription on rheumatoid arthritis patients. Altern Ther Health Med. 2004;10(1).

41. Chrubasik S, Eisenberg E, Balan E, et al. Treatment of low back pain exacerbations with willow bark extract: a randomized double-blind study. Am J Med. 2000;109(1):9-14. doi:10.1016/S0002-9343(00) 00442-3

42. Bliddal H, Rosetzsky A, Schlichting P, et al. A randomized, placebo-controlled, cross-over study of ginger extracts and ibuprofen in osteoarthritis. Osteoarthritis Cartilage. 2000;8(1):9-12. doi:10.1053/joca.1999.0264

43. Zhang GG, Lee W, Bausell B, et al. Variability in the traditional Chinese medicine (TCM) diagnoses and herbal prescriptions provided by three TCM practitioners for 40 patients with rheumatoid arthritis. J Altern Complement Med. 2005;11(3):415-421. doi:10.1089/acm.2005.11.415

44. Xu H, Arita H, Hayashida M, et al. Pain-relieving effects of processed Aconiti tuber in CCI-neuropathic rats. J Ethnopharmacol. 2006;103(3):392-397. doi:10.1016/j.jep.2005.08.050

45. Bensoussan A, Myers SP, Carlton AL. Risks associated with the practice of traditional Chinese medicine: an Australian study. Arch Fam Med. 2000;9(10):1071-1078. doi:10.1001/archfami.9.10.1071

46. Michalsen A, Klotz S, Lüdtke R, et al. Effectiveness of leech therapy in osteoarthritis of the knee: a randomized, controlled trial. Ann Intern Med. 2003;139(9):724-730. doi:10.7326/0003-4819-1399-200311040-00006

47. Hinoshita F, Ogura Y, Suzuki Y, et al. Effect of orally administered shao-yao-gan-cao-tang (Shakuyaku-kanzo-to) on muscle cramps in maintenance hemodialysis patients: a preliminary study. Am J Chin Med. 2003;31(3):445-453. doi:10.1142/S0192415X03001144
48. Molassiotis A, Fernández-Ortega P, Pud D, et al. Use of complementary and alternative medicine in cancer patients: a European survey. Ann Oncol. 2005;16(4):655-663. doi:10.1093/annonc/mdi110

49. Walker CI, Trevisan G, Rossato MF, et al. Antinociceptive activity of Mirabilis jalapa in mice. J Ethnopharmacol. 2008;120(2):169-175. doi:10.1016/j.jep.2008.08.002

50. Park JJ, Shin J, Choi Y, et al. Integrative package for low back pain with leg pain in Korea: a prospective cohort study. Complement Ther Med. 2010;18(2):78-86. doi:10.1016/j.ctim.2010.02.003

51. Kanodia AK, Legedza AT, Davis RB, Eisenberg DM, Phillips RS. Perceived benefit of Complementary and Alternative Medicine (CAM) for back pain: a national survey. JABFM. 2010;23 (3):354-362. doi:10.3122/jabfm.2010.03.080252

52. Ishola IO, Akindele AJ, Adeyemi OO. Analgesic and anti-inflammatory activities of Cnestis ferruginea Vahl ex DC (Connaraceae) methanolic root extract. J Ethnopharmacol. 2011;135 (1):55-62. doi:10.1016/j.jep.2011.02.024

53. Park $\mathrm{YG}$, $\mathrm{Ha} \mathrm{CW}$, Han $\mathrm{CD}$, et al. A prospective, randomized, double-blind, multicenter comparative study on the safety and efficacy of Celecoxib and GCSB-5, dried extracts of six herbs, for the treatment of osteoarthritis of knee joint. J Ethnopharmacol. 2013;149 (3):816-824. doi:10.1016/j.jep.2013.08.008

54. Xu C, Xu W, Xu H, et al. Role of puerarin in the signalling of neuropathic pain mediated by $\mathrm{P} 2 \mathrm{X} 3$ receptor of dorsal root ganglion neurons. Brain Res Bull. 2012;87(1):37-43. doi:10.1016/j. brainresbull.2011.10.007

55. Rodrigues MR, Kanazawa LK, Das Neves TL, et al. Antinociceptive and anti-inflammatory potential of extract and isolated compounds from the leaves of Salvia officinalis in mice. J Ethnopharmacol. 2012;139(2):519-526. doi:10.1016/j.jep.2011.11.042

56. Gao T, Hao J, Wiesenfeld-Hallin Z, Wang DQ, Xu XJ. Analgesic effect of sinomenine in rodents after inflammation and nerve injury. Eur J Pharmacol. 2013;721(1-3):5-11. doi:10.1016/j. ejphar.2013.09.062

57. Li JC, Shen XF, Meng XL, Zhang Y, Lai XR. Analgesic effect and mechanism of the three TCM-herbal drug-combination Tou Feng Yu pill on treatment of migraine. Phytomedicine. 2011;18(8-9):788-794. doi:10.1016/j.phymed.2011.01.008

58. Chopra A, Saluja M, Tillu G, et al. Ayurvedic medicine offers a good alternative to glucosamine and celecoxib in the treatment of symptomatic knee osteoarthritis: a randomized, double-blind, controlled equivalence drug trial. Rheumatology (Oxford, England). 2013;52 (8):1408-1417. doi:10.1093/rheumatology/kes414

59. Xu CH, Wang P, Wang Y, et al. Pharmacokinetic comparisons of two different combinations of Shaoyao-Gancao Decoction in rats: competing mechanisms between paeoniflorin and glycyrrhetinic acid. J Ethnopharmacol. 2013;149(2):443-452. doi:10.1016/j. jep.2013.06.049

60. Medicine NCfCaA. What is Complementary and Alternative Medicine (CAM); 2002. Available from: https://www.cancer.gov/ about-cancer/treatment/cam. Accessed December 31, 2020.
Journal of Pain Research

\section{Publish your work in this journal}

The Journal of Pain Research is an international, peer reviewed, open access, online journal that welcomes laboratory and clinical findings in the fields of pain research and the prevention and management of pain. Original research, reviews, symposium reports, hypothesis formation and commentaries are all considered for publication. The manuscript management system is completely online and includes a very quick and fair peer-review system, which is all easy to use. Visit http:// www.dovepress.com/testimonials.php to read real quotes from published authors. 